\title{
ATUALIDADE DA DIVISÃO SEXUAL E CENTRALIDADE DO TRABALHO DAS MULHERES
}

\author{
RELEVANCE OF SEXUAL DIVISION AND CENTRALITY \\ OF WOMEN'S WORK
}

\author{
Helena Hirata* \\ Danièle Kergoat ${ }^{* *}$
}

\begin{abstract}
Resumo
Começamos com as definições de divisão sexual do trabalho e relações sociais de sexo, mostrando a atualidade teórica desses conceitos para pensar a definição do trabalho e sua centralidade, inclusive sob o regime neoliberal, mas também a atualidade política para compreender e analisar os movimentos populares e feministas que se desenvolvem atualmente no mundo inteiro. Apresentaremos em particular a participação das mulheres no movimento dos Coletes Amarelos na França, em 2018 e 2019, e o sentido das suas lutas atuais. Em seguida, mostraremos, a partir do exemplo do trabalho de cuidado, as variabilidades e as permanências da divisão sexual do trabalho: diferenças no espaço da divisão do trabalho entre homens e mulheres, que podemos apreender pela metodologia da comparação internacional e permanências no tempo da divisão sexual, que tem a ver com a correlação de forças entre homens e mulheres na sociedade, isto é, com as relações sociais de sexo. Em contraponto à análise das mulheres participantes do Coletes Amarelos, apresentaremos a mobilização das cuidadoras e auxiliares de enfermagem nas instituições de longa permanência de idosos na França, em 2017 e 2018, que mostram a forte correlação entre política e trabalho. Palavras-chave: Divisão sexual do trabalho. Relações sociais de sexo. Mobilizações feministas. Trabalho do care.
\end{abstract}

\begin{abstract}
We begin with the definitions of sexual division of labor and sexual social relations, to show the theoretical relevance of these concepts to think about the definition of work and its centrality, including under the neoliberal regime, but also the political relevance to understand and analyze the popular and feminist movements that are developing currently worldwide. We will present particularly the participation of women in the Yellow Vests movement in France between 2018 and 2019, and the meaning of their current struggles. Then we will show, from the example of care work, the variability and permanence of the sexual division of labor: differences in the space of the division of labor among men and women, which we can apprehend through the methodology of international comparison, and the permanence in time of sexual division, which has to do with the correlation of forces between men and women in society, that is, with gender social relations. In contrast to the analysis of women in Yellow Vests, we will present the mobilization of caregivers and nursing assistants in long-term care institutions for the elderly in France, between 2017 and 2018, which show the strong correlation between politics and work.
\end{abstract}

Keywords: Sexual division of labour. Gender social relations. Feminist movements. Care work.

\footnotetext{
* Socióloga. Diretora de pesquisa emérita do Centre National de la Recherche Scientifique (CNRS) e pesquisadora colaboradora do Programa de Pós-Graduação em Sociologia da USP. Áreas de pesquisa: trabalho e divisão sexual do trabalho, gênero e globalização, teorias e práticas do cuidado numa perspectiva comparada. Publicações: 1) Nova divisão sexual do trabalho? Um olhar voltado para a empresa e a sociedade. São Paulo: Boitempo, 2002; 2) com LABORIE, F; LE DOARÉ, H.; SENOTIER, D. (coord.). Dicionário crítico do feminismo. São Paulo: Edunesp, 2009; 3) com PAIVA ABREU, R. de.; LOMBARDI, M. R. (org.). Gênero e trabalho no Brasil e na França. Perspectivas interseccionais. São Paulo: Boitempo, 2016; 4) com GUIMARÃES, N. A. O gênero do cuidado. São Paulo: Ateliê, 2020.

** Socióloga. Diretora de pesquisa honorária do Centre National de la Recherche Scientifique (CNRS) e fundadora do Groupe d'Études sur la Division Sociale et Sexuelle du Travail (GEDISST), atual Genre, Travail, Mobilités (GTM). Ela é responsável pela coleção Le genre du monde da Editora La Dispute. Áreas de pesquisa: divisão sexual do trabalho, relações sociais de sexo, operárias, movimentos sociais e emancipação. Publicações: 1) Les ouvrières. Paris: Sycomore, 1982; 2) Les femmes et le travail à temps partiel. Paris: Ministère du travail, de l'emploi et de la formation Professionnelle, 1984; 3) com IMBERT, F.; LE DOARÉ, H.; SENOTIER, D. Les infirmières et leur coordination 1988-1989. Paris: Lamarre, 1992; 4) Lutar, dizem elas...Recife: Ed. SOS Corpo, 2018.
} 


\section{Retomando as definições de divisão sexual do trabalho e relações sociais de sexo}

A problemática da divisão sexual do trabalho e a questão correspondente de relações sociais de sexo têm uma longa história. Elas nascem na França, no fim dos anos 1970, num contexto social e econômico bastante particular: o do movimento feminista da segunda onda e de movimentos sociais então muito fortes, com a emergência de novos atores até então invisibilizados (os jovens, as mulheres, os/as imigrantes). Também se deve lembrar o movimento maciço de assalariamento crescente das mulheres, iniciado nos anos 1960.

Em tal contexto, tratava-se para nós, sociólogas feministas, de destrinchar as velhas conceitualizações em vigor na Sociologia. A partir da afirmação de que o trabalho doméstico era trabalho, no sentido pleno, contestamos a separação entre Sociologia da Família e Sociologia do Trabalho, mostrando que a teorização em termos de papéis sociais era inadequada para pensar a realidade do trabalho. Afirmamos que era impossível falar de divisão social do trabalho ancorando-a na doxa marxista, sem dar um lugar determinante à divisão sexual do trabalho. Falamos, a propósito dessa reconceitualização do trabalho, de "revolução copernicana" (DELPHY; KERGOAT, 1982).

Que definição dávamos e damos ainda hoje? A divisão sexual do trabalho tem por característica a atribuição prioritária das mulheres à esfera reprodutiva enquanto os homens são designados à esfera produtiva. Paralelamente, os homens captam as funções de forte valor social agregado (políticas, religiosas, militares etc.). Quanto à estrutura mesma da divisão sexual do trabalho, trata-se em primeiro lugar da separação entre "trabalho de homem" e "trabalho de mulher". Todas as sociedades conhecidas operam segundo essa separação. Separação, mas também, e sobretudo, hierarquização: um trabalho de homem vale mais do que um trabalho de mulher, tanto no plano simbólico quanto no plano econômico (KERGOAT, 2000).

Entretanto, se esses princípios organizadores se encontram em todas as sociedades conhecidas, a História e a Antropologia mostraram a variabilidade extrema das modalidades da divisão sexual do trabalho: tal profissão masculina numa sociedade será considerada feminina em outra. A mesma constatação pode ser feita em relação às empresas.

Quanto às relações sociais, elas estão na origem dessa forma de divisão social do trabalho. As relações sociais organizam, isto é, nomeiam e hierarquizam as divisões da sociedade: privado/público, trabalho manual/trabalho intelectual, capital/trabalho, divisão internacional do trabalho etc. As modalidades materiais dessas bicategorizações antagônicas são o que está em jogo (l'enjeu) nas relações sociais: a divisão social do trabalho entre os sexos é o que está fundamentalmente em jogo nas relações sociais de sexo.

Assim como a divisão sexual do trabalho, as relações sociais possuem princípios organizadores. Distinguimos quatro deles: a exploração (extorsão do sobretrabalho de um grupo social por outro), a dominação (ou violência simbólica), a opressão (que recobre todas as formas de violência física), a apropriação ("colocar à disposição ótima do empregador/a que assegura 
de facto a exposição permanente dos corpos ao trabalho a ser realizado" $\left.{ }^{1}\right)$. Apenas quando uma relação social acumula essas quatro propriedades, pode-se afirmar que se trata de uma relação transversal e estruturante de toda a formação social considerada. As relações sociais de sexo são uma perfeita ilustração desse esquema.

\section{Conceitualizar outra forma o trabalho}

Levar isso centralmente em conta é indispensável para poder elaborar o conceito de trabalho em toda sua extensão. Como já observamos (KERGOAT, 2018), o trabalho é uma "atividade paradigmática" (VINCENT, 1987) no sentido em que ele é central sociologicamente, porque é um mediador privilegiado das relações entre indivíduo e sociedade, e central politicamente, porque é ele que organiza a produção do viver em sociedade (HIRATA; ZARIFIAN, 2000), e é através dele que podemos colocar o problema da emancipação.

Essa centralidade do trabalho parecia evidente quando em torno dele se organizavam a maior parte dos movimentos sociais significativos e o movimento operário era forte na França. Mas a centralidade do trabalho permanece nesses tempos de desemprego, de globalização, de empreendedorismo e de uberização do emprego, pois é segundo essas mediações que a sociedade - tanto francesa quanto brasileira - reconfigura-se atualmente.

Compreender as sociedades atuais e sua evolução passa, portanto, pelo reconhecimento da centralidade do trabalho. Mas não é a partir de qualquer conceitualização do trabalho. Ela necessita levar em conta o "trabalho reprodutivo" (como fizeram as feministas italianas) ou, como teorizou a escola francesa da divisão sexual do trabalho, o "trabalho doméstico", entendendo que ele recobre tanto o trabalho doméstico quanto o trabalho parental ou o trabalho doméstico de saúde.

Uma digressão se impõe. As duas noções designam sensivelmente a mesma realidade empírica, porque para nós o trabalho doméstico remetia ao conjunto do trabalho reprodutivo, prova disso é o título da coletânea $O$ sexo do trabalho. Estruturas familiares e sistema produtivo (COLLECTIF, 1984). Os conceitos de "trabalho reprodutivo" e "trabalho doméstico", contudo, foram elaborados em contextos sociais muito diferentes: a maioria da população feminina italiana dos anos 1970 era constituída do que se convencionou chamar "donas de casa". A situação das francesas era diferente, pois, como lembrávamos no início deste artigo, os anos 1960 tinham visto uma explosão do assalariamento feminino na França.

O que nos importava não era, portanto, descobrir, no contexto político dos anos 1970, na Itália, novos conceitos extraídos de uma leitura exegética da obra de Marx (FEDERICI, 2019), nem uma nova jazida de atores potencialmente revolucionários (DALLA COSTA; JAMES, 1973), mas, sociologicamente, dar um estatuto dinâmico à articulação entre trabalho assalariado e trabalho doméstico, seguindo nisso o espírito do feminismo da segunda onda que afirmava

1 Para o conceito de apropriação, ver Guillaumin (1992). 
que "o privado é político" e proclamava seu "saco cheio" do trabalho gratuito e invisível, que é o trabalho doméstico. É, portanto, indispensável levar em consideração a divisão sexual do trabalho para pensar a divisão social do trabalho, tanto como conceito quanto como realidade empírica.

Isso porque o período atual passa por uma reestruturação profunda do aparelho produtivo. Como em todos os períodos similares que o precederam, observa-se movimentos muito intensos de redefinição das qualificações e de redistribuição da mão de obra: surgem novas profissões, muitas qualificações se tornaram obsoletas e não podem mais servir de base a uma equivalência "diploma-qualificação-classificação". Esse movimento é acompanhado de uma bipolaridade acentuada entre trabalho manual e trabalho intelectual.

\section{A divisão sexual do trabalho: um instrumento poderoso para compreender as mutações do período atual}

Simultaneamente, em âmbito mundial, as populações migram - por razões climáticas, econômicas ou políticas -, para tentar encontrar um abrigo, um trabalho, um ganha-pão. Mas, se essas populações conseguem chegar a um país "rico", elas se encontram diante de um mercado de trabalho degradado, precarizado, uberizado, desregulado e da oferta de trabalho desqualificado. A (super) exploração é renovada nas suas formas e intensificada, sendo uma situação comum aos homens e às mulheres.

É esse o horizonte em que evolui atualmente a divisão sexual do trabalho. Se nesse novo contexto suas modalidades se transformaram, sua estrutura é notavelmente perene. "Trabalho de homem" e "trabalho de mulher" continua sendo uma oposição atual, mesmo se os trabalhos de uns e outros se modificaram (FALQUET, 2006). Pode-se dizer a mesma coisa quanto à hierarquização dos empregos: reconhece-se que o emprego de armas necessita de um mínimo de aprendizagem, a coisa muda totalmente no que diz respeito aos empregos femininos em pleno desenvolvimento nos países do Norte. Pensamos principalmente nos serviços de cuidado ou de limpeza (crianças, pessoas idosas, arrumação das casas e dos locais de trabalho). Essas profissões requerem qualidades que são consideradas inatas (pelo sexo, mas também pela origem étnica), e não adquiridas por uma aprendizagem: são fatos da natureza e não da cultura. Dessa forma, não há necessidade de retribui-las convenientemente. É como se a menina originária de classes populares, por sua educação específica de futura reprodutora e o exercício cotidiano do trabalho doméstico, não precisasse adquirir as qualidades para exercer esses empregos. Assim, essas mulheres não são babás ou diaristas porque não foram formadas ou foram mal formadas pelo aparelho escolar, mas porque elas são bem formadas pelo conjunto do trabalho reprodutivo - que elas devem assegurar dado o seu lugar na divisão sexual do trabalho e, mais amplamente, na divisão social no seu conjunto. 
Ao mesmo tempo, a aquisição dos saber-fazer requeridos pelo mercado de trabalho, sendo realizada amplamente fora dos canais institucionais de qualificação e sempre em referência à esfera do privado, aparece-lhes como uma aquisição individual, natural e não coletiva: elas interiorizam a banalização de sua própria qualificação e se encontram, por isso, pouco armadas quando se trata de negociar um salário conveniente. Esse é um dos principais obstáculos à mobilização coletiva dessas mulheres. Mas, como veremos mais adiante, as formas atuais do neoliberalismo se têm de início efeitos opressores para a mão de obra globalizada, têm também efeitos inesperados em termos de mobilização.

\section{Centralidade do trabalho das mulheres: suas mobilizações}

É também num outro nível que convém interrogar a realidade. A consideração do trabalho feminino é central para compreender o funcionamento das sociedades desenvolvidas atuais. Como sublinhava Pierre Rimbert em seu artigo O poder insuspeitado das trabalhadoras (RIMBERT, 2019), essas sociedades parariam simplesmente de funcionar se não houvesse o trabalho de todas essas mulheres: professoras, puericultoras, enfermeiras, cuidadoras, trabalhadoras domésticas, diaristas, agentes de limpeza etc.

Os sindicatos têm dificuldade em medir esse fenômeno, pois sua história se construiu a partir da figura do trabalhador operário, masculino, branco, operando nas minas ou metalúrgico. E, consequentemente, não conseguem mensurar o poder subversivo potencial dessas trabalhadoras. Esses empregos, não deslocáveis, são para as mulheres e apenas para elas.

Entretanto emergem movimentos em escala mundial, o que torna urgente levar em consideração as novas formas de conflitualidade. É o que quis testemunhar um livro como Feminismo para os 99\%. Um manifesto (ARRUZZA; BHATTACHARYA; FRASER, 2019). No Brasil, na Índia, em Israel, no Líbano, é a luta das trabalhadoras domésticas. Na Espanha, em 2018, cinco milhões de manifestantes desfilaram contra as violências tanto patriarcais quanto capitalistas; é também o movimento mundial de \#MeToo. Na França, é a jornada contra as violências às mulheres, no dia 23 de novembro de 2019, que reuniu 49 mil manifestantes em Paris. É também a intensa preparação da greve que acompanhou o 8 de março de 2020 ("Paramos todas"). E é, enfim, a participação maciça das mulheres no movimento dos Coletes Amarelos. 


\section{As mulheres no movimento dos Coletes Amarelos}

Esse movimento ${ }^{2}$ incandesceu a França durante muitos meses, sobretudo a partir de 17 de novembro de 2018. Ele colocou o governo em dificuldade em alguns momentos. Tratou-se da radicalização das classes populares, em que se reencontraram lado a lado múltiplas categorias socioprofissionais modestas: empregados assalariados, precários ou não, mas em todo caso com baixa remuneração, pequenos empresários, empreendedores tipo MEI (microempreendedor individual), desempregados, mas também sem-teto, aposentados e aposentadas, pessoas com deficiência etc.

A mídia francesa se referiu a esse movimento quase unicamente através das violências, reais ou supostas, que acompanharam as manifestações, que contaram também com assembleias gerais, realizadas regularmente nas regiões, e com a elaboração de pautas de reivindicações.

As mulheres, como dissemos, foram muito ativas nesse movimento. Não se tratava de mulheres quaisquer, mas de mulheres provenientes das classes populares que se insurgiram contra a precariedade de seus empregos, seus baixos salários, a queda drástica da proteção social, a supressão programada dos serviços públicos, sua condição (no caso das mães solteiras), mas também contra o desprezo do poder pelos pequenos, pela "gentinha".

Se todas contestam o peso do sistema político face à sua vida profissional (ou à ausência de vida profissional, no caso das desempregadas) e à sua vida privada, algumas foram mais longe, denunciando o aspecto sistêmico das violências exercidas contra as mulheres, a violência das relações sociais de classe e das relações sociais de sexo, a apropriação singular do trabalho das mulheres e de seus corpos através da supressão programada dos serviços públicos

É, portanto, a divisão sexual do trabalho que permite dar conta da mobilização dessas mulheres e de muitas outras no mundo inteiro, bem como das modalidades dessa mobilização.

\section{Divisão sexual do trabalho: permanência e variabilidade}

Na segunda parte deste artigo, queremos utilizar outra chave para a compreensão da divisão sexual do trabalho: as variabilidades no espaço e a permanência no tempo da divisão sexual do trabalho, a partir do recurso metodológico das comparações internacionais.

\footnotetext{
2 Esse movimento apareceu na França em outubro de 2018. Trata-se de um movimento social que começou de forma espontânea contra o aumento do preço da gasolina. Sua origem está nas redes sociais. A partir de novembro de 2018, a visibilidade crescente do movimento apoiou-se, de um lado, numa manifestação todos os sábados em praticamente todas as cidades relativamente importantes da França e, de outro, no bloqueio das estradas e das encruzilhadas nas zonas menos urbanizadas. Nas metrópoles, essas manifestações do sábado eram acompanhadas frequentemente de violências (contabilizou-se muitos milhares de pessoas feridas, na maioria das vezes manifestantes). São essas violências, o caráter esporádico do movimento, seu aspecto espontâneo (a recusa do princípio de delegação) que atraíram a atenção da mídia. Entretanto trata-se de um trabalho militante considerável. Rapidamente, as reivindicações do movimento adquiriram dimensões sociais e políticas. Assembleias gerais foram regularmente realizadas no interior da França e listas de reivindicações foram elaboradas. Deve-se acrescentar que no dia 12 de dezembro de 2020 foi festejado, com manifestações em Paris e em toda a França, o segundo aniversário do movimento.
} 
Já tínhamos conceitualizado a permanência e as variabilidades na divisão sexual do trabalho em termos de sincronia e diacronia (HIRATA, 1995). Dizíamos, nesse artigo de 1995, que tanto a variabilidade quanto a persistência da divisão sexual do trabalho podem ser encontradas no tempo e no espaço, mas que a diacronia é a dimensão privilegiada para apreender a permanência, assim como a sincronia para apreender a variabilidade. A comparação de diversos espaços nacionais permite apreender as diferenças entre os sexos, assim como a comparação no tempo permite constatar o que permanece nas relações sociais entre os sexos. Esse paradoxo aparente - persistência na variabilidade - remete à imbricação, na divisão sexual do trabalho, de relações sociais que não são periodizáveis da mesma maneira. As dimensões constitutivas do tempo das relações sociais de sexo (evolução, rupturas e continuidades) não são as mesmas que as dimensões constitutivas do tempo das relações sociais capital-trabalho. Assim, esses dois tempos não são periodizáveis da mesma forma. Poderíamos levantar a hipótese de que as mudanças na divisão sexual do trabalho remetem às conjunturas econômicas e às relações de classe, o que não quer dizer que as correlações de força entre os sexos não desempenhem um papel nessas mudanças, e que as permanências remetem mais às relações sociais de sexo, ou a uma das dimensões temporais dessas relações.

Também no texto citado afirmávamos a importância dos movimentos sociais, e em particular dos movimentos feministas, para a criação de uma correlação de forças que fosse no sentido de uma modificação ou não das relações sociais entre os sexos. A partir de um olhar sobre o que muda na divisão sexual do trabalho, poderíamos dizer que o que parece sobredeterminante é o tipo de correlação de forças entre os homens e as mulheres na sociedade, correlações de forças institucionalizadas ou não, mas que são frequentemente o resultado de amplas lutas sociais, de movimentos sociais e, sobretudo, da existência ou não de movimentos feministas e de atividades conscientes em vista de uma transformação das relações sociais.

\section{Permanência da divisão sexual do trabalho:} a centralidade do trabalho das mulheres no trabalho de cuidado

Uma primeira permanência notável nos três países em que foi desenvolvida pesquisa sobre o trabalho de cuidado é a centralidade do trabalho das mulheres. Elas têm um papel central porque são provedoras de cuidados gratuitos no domicílio e cuidados profissionais em instituições e nas residências fora de sua família. Elas têm um papel central porque a sociedade atribui o trabalho doméstico e de cuidado a um dos sexos, cristalizando, dessa forma, a divisão sexual do trabalho, tanto profissional quanto doméstico, entre homens e mulheres.

O care pode ser definido como um conjunto de práticas materiais, emocionais e psicológicas que dão respaldo às necessidades dos outros. $\mathrm{O}$ care, o cuidado, foi exercido e continua a sê-lo no espaço doméstico, na esfera dita "privada", e realizada "por amor" junto às pessoas idosas, às crianças, aos doentes, às pessoas com deficiências físicas e mentais. 
A centralidade do trabalho das mulheres pode ser constatada também no quadro da nova divisão sexual e internacional do trabalho. A análise do trabalho do care confirma a centralidade do trabalho feminino nas instituições e no domicílio, realizado gratuitamente ou a título de atividade remunerada. A despeito das diferenças societais, esse trabalho é realizado pelas mulheres, com algumas exceções a que nos referiremos adiante, e provavelmente continuará sendo, por se tratar de um trabalho precário, com baixos salários, pouco reconhecido e valorizado. A organização social do cuidado (OSC) atribui um papel central à mulher e à família.

Para além das grandes diferenças entre Brasil, França e Japão, tanto pelo seu nível de desenvolvimento econômico e tecnológico, quanto por sua história sociopolítica e cultural, esses três países fazem face ao envelhecimento rápido de sua população e à falta de mão de obra gratuita das mulheres, que nos três países estão cada vez mais presentes no mercado de trabalho e não podem mais se ocupar das pessoas dependentes no seio de sua própria família. É esse duplo fenômeno que engendra o que é chamado de "crise do cuidado". Ele teve como consequência o desenvolvimento das profissões relacionadas ao cuidado e à mercantilização e externalização crescentes desse trabalho.

A centralidade do trabalho das mulheres é tanto quantitativa, pela inserção maciça das mulheres no mercado de trabalho, quanto qualitativa, pois seu investimento é essencial para o trabalho reprodutivo e pelo fato de que elas estão nas profissões de produção da vida, as profissões do care. Podemos observar a centralidade do trabalho das mulheres tanto realizado gratuitamente quanto como atividade remunerada, nas instituições e nos domicílios.

As principais atrizes e os principais atores do care, além das cuidadoras, o Estado, mercado, família e comunidade, agem em cada país de maneira desigual e assimétrica, mas as mulheres continuam a realizar majoritariamente o trabalho do care e em domicílio. No Brasil, são as trabalhadoras domésticas e as diaristas sem registro; na Europa, as mulheres imigrantes e muitas vezes sem documentos; no Japão são as mulheres que acumulam frequentemente o cuidado em relação aos pais idosos e o trabalho de care remunerado em domicílio. A imbricação das relações sociais se faz diferentemente em cada país (KERGOAT, 2016), mas a organização social do care atribui de maneira constante um papel central às mulheres e à família nos três países estudados.

\section{Variabilidade no espaço da divisão sexual do trabalho: os homens no trabalho de cuidado no Japão}

O grande número de homens que trabalham como cuidadores nas instituições japonesas, shisetsu, é bastante surpreendente, sobretudo, quando se sabe o quanto o care é considerado um trabalho de mulher no espaço doméstico. Na França, pouco mais de 10\% dos profissionais de cuidados eram homens nas instituições de longa permanência de idosos. Nas instituições similares no Brasil (ILPI), eles eram menos de 5\%. Nos shisetsu do Japão, eles chegavam a quase 
40\%. Em números absolutos, do total de 265 cuidadoras(es) entrevistadas(os) nos três países, 215 eram mulheres (81\%) e 50 homens (19\%). No Brasil, foram entrevistadas(os) 82 mulheres e 4 homens; na França, 82 mulheres e 13 homens; no Japão, 51 mulheres e 33 homens. Mais de 95\% dos cuidadores no Brasil eram mulheres. Na França, eram quase 90\%.

Os homens e as mulheres japoneses entrevistadas(os) consideravam que o ambiente misto é um aspecto positivo de suas atividades. Os depoimentos de alguns deles se assemelham aos ouvidos em pesquisas efetuadas na indústria. "É melhor ter um homem. Existem tarefas que exigem força física. E a atitude dos homens também se modifica quando há mulheres presentes" (trabalhador do care, 42 anos). Mas outras considerações foram menos previsíveis: "De uma maneira geral, é melhor ter os dois, homens e mulheres. Pode-se beneficiar da maneira diferente de ver as coisas" (trabalhador do care, 50 anos). Ou ainda, "pode-se, assim, ter os bons lados de cada um, homens e mulheres" (trabalhador do care, 26 anos). Há um paradoxo evidente nesse investimento feito pelos homens em tarefas consideradas tradicionalmente como femininas tomar conta de pessoas idosas, dar banho, alimentar, levá-las ao banheiro, vestir, mas também, conversar com elas e interagir -, se levarmos em conta a tradição, ainda muito machista, da divisão do trabalho profissional e doméstico na sociedade japonesa.

Diversas explicações podem ser encontradas para essa variabilidade na divisão sexual do trabalho do cuidado que a comparação internacional revela. A mais importante parece ser a crise econômica que atingiu o Japão com a falência da Lehman Brothers, em 2008, o que provocou desemprego em massa de homens que estavam no setor industrial ou no setor financeiro (bancos e companhias de seguros). O governo japonês propôs a formação gratuita para a profissão de cuidador com garantia de emprego numa instituição de longa permanência de idosos ao final da formação profissional. Trabalhar numa atividade tradicionalmente feminina era uma alternativa melhor do que o desemprego. Entre o não trabalho ou o desemprego e o trabalho no setor do care, a escolha dos homens japoneses foi clara. A despeito das dificuldades e da penosidade ligadas a essa atividade, o emprego nesse setor em expansão abriu perspectivas de carreira e certa estabilidade, frente à terrível experiência do desemprego. Também desde 2000, com a implantação do LTCI (Long Term Care Insurance ${ }^{3}$ ) houve, da parte do governo, uma propaganda maciça nas mídias quanto à nova profissão de cuidador de idosos como perspectiva para os jovens formandos de ambos os sexos. Foram as instituições de longa permanência de idosos que acolheram os candidatos homens para desempenhar o trabalho de cuidador, pois no cuidado em domicílio, que requer a realização simultânea do trabalho doméstico e de cuidados, são as mulheres essencialmente que o realizam.

3 O LTCI (Long Term Care Insurance) ou kaigo hoken é o principal instrumento de políticas públicas do governo japonês, implementado em 2000, para o cuidado de pessoas idosas dependentes. Ele é financiado por um imposto obrigatório para os japoneses ou estrangeiros residentes de 40 anos ou mais e propicia o acesso dos idosos, a partir de 65 anos, a uma instituição ou ao auxílio de uma cuidadora domiciliar. 


\section{Permanências na divisão sexual do trabalho: "teto de vidro" e desigualdades salariais}

Como em pesquisas realizadas nos anos 1980 e 1990 no setor industrial, pudemos constatar que os postos de direção e de supervisão são geralmente ocupados por homens nos três países, e que o fato de as mulheres serem majoritárias entre as cuidadoras não garante a elas o acesso aos postos de "líder" ou de diretoras. A feminização dos postos de direção era mais importante na França do que no Japão ou no Brasil, o que seríamos tentadas a atribuir à força dos movimentos feministas pela igualdade entre os sexos no primeiro país.

Uma segunda permanência notável, apesar das diferenças de tratamento entre homens e mulheres nos países, diz respeito às desigualdades salariais. Se já afirmamos em outros textos a permanência da desigualdade de remuneração entre os sexos a partir de uma perspectiva diacrônica, na temporalidade de um século (HIRATA, 2018), podemos afirmar que as profissionais mulheres do cuidado recebem, nas instituições, salários inferiores aos dos seus homólogos masculinos. Para além das desigualdades salariais entre homens e mulheres, há desigualdades salariais substanciais entre os países: salários maiores no Japão para os dois sexos, salários inferiores no Brasil para os dois sexos, a França ficando numa situação intermediária. Os salários mais altos no Japão se explicam principalmente pela existência do "bônus": um salário suplementar pago duas vezes ao ano, representando três a quatro salários mensais e beneficiando os assalariados regulares na empresa. Outra desigualdade entre os países que repercute sobre os salários é a prática de horas extras sem remuneração, que é constante no setor de cuidados nos anos 2000, como era usual nos anos 1980 no setor industrial, conforme pesquisa sobre firmas multinacionais no Brasil, na França e no Japão (HIRATA, 2020).

\section{Cuidadoras(es) e percepções do cuidado: similitudes}

A partir de um pequeno grupo de entrevistadas(os), podemos levantar alguns pontos sobre as diferenças e similaridades na atividade de cuidado no Brasil, França e Japão. Analisando em profundidade nove entrevistas, seis mulheres e três homens ${ }^{4}$, três em cada país, encontramos várias semelhanças entre mulheres e homens, e entre os trabalhadores e trabalhadoras dos três países, na maneira de conceber o care e na realização da atividade de cuidado.

$\mathrm{Na}$ atividade de cuidado, há uma série de convergências entre a disposição das cuidadoras e cuidadores dos três países. Uma primeira é a ideia de presença associada ao care. Cuidar é estar presente, e a presença é sempre para um indivíduo e não para uma multiplicidade de pessoas. Quando se trata de muitas pessoas, a possibilidade de garantir a presença se esvai. Uma segunda convergência é a diferença na resposta sobre "o que é o cuidado" e "em que consistem suas atividades". A questão sobre o que é o cuidado remete à disposição e coloca o cuidador na dimensão da ética e do trabalho concreto. O care é pensado em relação a um indivíduo singular,

4 Para uma apresentação detalhada das entrevistas, ver Hirata (2020). 
as "atividades" nos põem na presença de um coletivo, à necessidade de cooperação e a níveis de dependência diferentes segundo os indivíduos. A terceira convergência: o care e as "atividades" são pensados como ajuda por três cuidadoras mulheres e por um cuidador homem. A noção de "ajuda" relacionada ao "cuidado" aparece de maneira recorrente. A quarta convergência: as atividades se referem não apenas à dimensão fisiológica, mas também à dimensão psicológica e, entre as disposições, a paciência é necessária para realizar essas atividades.

Embora as diferenças societais entre os três países considerados sejam significativas na definição do que é o cuidado e nas diferentes atividades, tais como elas são expressas pelas trabalhadoras e trabalhadores entrevistadas(os), não foi possível constatar diferenças importantes, mas sim similitudes nas disposições e nas práticas.

\section{Cuidadoras(es) e percepções do salário e dos problemas de saúde: similitudes}

As cuidadoras e cuidadores têm a mesma percepção dos salários, considerados baixos nos três países, a despeito das desigualdades salariais entre eles. A ideia de um não reconhecimento do valor monetário do trabalho do cuidado é recorrente no Japão, como na França e no Brasil, e expressa por mulheres e homens. A diferença entre os sexos se encontra no argumento sobre as consequências desses baixos salários: os homens empregados, sobretudo no Japão, consideram que eles não poderiam se casar e fundar uma família com os salários que recebem.

Outro ponto de semelhança é relativo aos problemas de saúde no trabalho, sobretudo, lombalgias e hérnias de disco, declarados como males muito frequentes nos três países, tanto pelas mulheres quanto pelos homens. Não há, da parte da direção dos estabelecimentos, nenhuma prática preventiva para evitar essas dores incapacitantes de que praticamente todos os trabalhadores, homens e mulheres, se queixam.

\section{Divisão sexual do trabalho e mobilizações femininas no setor do cuidado}

A variável sindical deve ser levada em conta para explicar a diferença nas mobilizações no setor de cuidado. Quando avaliamos as entrevistas realizadas nos três países, é preciso notar que as respostas das(os) entrevistadas(os) são mais uniformes e padronizadas no Japão. Nesse país, há pouca contestação da organização do trabalho e da atitude da direção. Na França, os sindicatos estão mais presentes e os discursos manifestam mais frequentemente desacordos com a direção.

O setor de cuidado se mobilizou recentemente na França - em 2017 e 2018 - e não constatamos movimentos similares no Japão ou no Brasil. No Japão, não tivemos conhecimento da presença de sindicatos nas instituições pesquisadas. No Brasil, ainda há poucas associações de cuidadoras, e são os sindicatos de trabalhadoras domésticas que representam as cuidadoras. A profissão ainda não é regulamentada, pois o projeto de lei, aprovado pelo parlamento, não foi sancionado pelo presidente da República em 2019 (MORENO, 2019). 
Se as mulheres francesas que fazem parte do movimento dos Coletes Amarelos pertencem a vários setores da sociedade que formam as "classes populares", como assinalamos na primeira parte deste artigo, a mobilização das cuidadoras e auxiliares de enfermagem nas instituições de longa permanência de idosos na França, nos anos de 2017 e 2018, são movimentos que partem de uma categoria socioprofissional. Essas mobilizações foram realizadas contra as restrições orçamentárias do Ministério da Saúde, que provocaram intensificação do trabalho e um cuidado de má qualidade. Que sejam as mulheres o contingente maciço de grevistas não é de estranhar, sendo a categoria composta por quase $90 \%$ de mulheres nesse país. Trata-se de uma greve de 117 dias num estabelecimento situado em Foucherans, no leste da França (PELLETIER, 2019, p. 272-280). A reivindicação, que visa diretamente o Estado, foi de conceder financiamentos consequentes ao setor da saúde, para a criação de mais postos de trabalho que permitam às cuidadoras realizarem adequadamente o seu trabalho junto aos idosos (PELLETIER, 2019). A questão do "valor de uso" do seu trabalho remete à análise feita por Danièle Kergoat (KERGOAT et al, 1992) do movimento das enfermeiras na França, em 1988 e 1989, e a emergência de uma "nova figura salarial feminina". As trabalhadoras do care na França poderiam ser vistas como uma nova emergência dessa figura esboçada no movimento social das enfermeiras do fim dos anos 1980.

\section{Conclusão}

Analisamos os conceitos de divisão sexual do trabalho e de relações sociais de sexo com o objetivo de mostrar a sua atualidade, tanto teórica quanto política, tentando pensar através delas movimentos de resistência e de emancipação, como os das mulheres Coletes Amarelos e das cuidadoras de instituições no interior da França. Somos tentadas a considerar atual a reflexão de Hélène le Doaré segundo a qual "as condições respectivas do trabalho dos homens e das mulheres mudam segundo o contexto histórico, cultural, econômico, porém não se transformam - seguem obstinadamente a mesma linha de partilha dos espaços masculinos e femininos" (LE DOARE, 1994, p. 65).

Colocar a divisão sexual do trabalho e as relações sociais de sexo no centro dos dispositivos de análise permite não apenas tornar visíveis um grande número de fenômenos que passariam desapercebidos, mas igualmente dinamizar os conceitos de trabalho e de divisão social do trabalho e abordar de maneira inclusiva os movimentos sociais em toda a sua amplitude e diversidade. Colocar esses conceitos no centro da reflexão cidadã e feminista é uma necessidade ${ }^{5}$.

\section{Referências}

ARRUZZA, Cinzia ; BHATTACHARYA, Tithi ; FRASER, Nancy. Féminisme pour les 99\%. Un manifeste. Paris: La Découverte, 2019.

5 Esse artigo foi concebido e discutido pelas autoras. A redação da primeira parte é de Danièle Kergoat; a da segunda parte, que se inicia com "Divisão sexual do trabalho: permanência e variabilidade" foi redigida por Helena Hirata, que é também a tradutora da primeira parte, escrita originalmente em francês. 
COLLECTIF. Le sexe du travail. Structures familiales et système productif. Grenoble: Presses universitaires de Grenoble, 1984.

DALLA COSTA, Mariarosa; JAMES, Selma. Le pouvoir des femmes et la subversion sociale. Genève: Librairie Adversaire, 1973.

DELPHY, Christine; KERGOAT, Danièle. Les études et les recherches féministes et sur les femmes en sociologie. Femmes et recherche, pour quel féminisme. In: COLLOQUE FEMMES, FEMINISME, RECHERCHE, 1982, Toulouse. Rapport sur les recherches féministes du collectif parisien du colloque Femmes, féminisme, recherche. Toulouse, dez. 1982. p. 894.

LE DOARÉ, Hélène. Do poder político e poiético. Esquema de um raciocínio. Revista Estudos Feministas, Florianópolis, p. 65-75, 2 sem. 1994.

FALQUET, Jules. Hommes en armes et femmes « de service » : tendances néolibérales dans l'évolution de la division sexuelle et internationale du travail. Cahiers du genre, Paris, n. 40, p. 15-37, 2006.

FEDERICI, Silvia. Le capitalisme patriarcal, Paris: La Fabrique éditions, 2019.

GUILLAUMIN, Colette. Pratique du pouvoir et idée de Nature. In : GUILLAUMIN, Colette (org.). Sexe, Race et Pratique du pouvoir. L'idée de nature. Paris : Côté-femmes, 1992. p. 13-82.

HIRATA, Helena. Rapports sociaux de sexe et divisions du travail. Contribution à la discussion sur le concept du travail. In : BIDET, Jacque; TEXIER, Jacques (org.). La crise du travail, Paris : P.U.F, 1995. p. 81-92.

HIRATA, Helena; ZARIFIAN, Philippe. Travail (le concept de). In : HIRATA, Helena et al. (org.). Dictionnaire critique du féminisme. Paris: P.U.F, 2000. p. 230-235.

HIRATA, Helena. Classe, gênero, raça e movimentos sociais: a luta pela emancipação. Revista de Políticas Publicas, São Luís, v. 22, n. especial, p. 143-158, 2018.

HIRATA, Helena. Comparando relações de cuidado: Brasil, França, Japão. Revista Estudos Avançados, São Paulo, n. 98, p. 25-40, 2020.

KERGOAT, Danièle et al. Les infirmières et leur coordination 1988-1989. Paris : Lamarre, 1992.

KERGOAT, Danièle. Division sexuelle du travail et rapports sociaux de sexe. In : HIRATA, Helena et al. (org.). Dictionnaire critique du féminisme. Paris : P.U.F, 2000. p. 35-44.

KERGOAT, Danièle. Le care et l'imbrication des rapports sociaux. In : GUIMARÃES, Nadya Araújo; MARUANI, Margaret; SORJ, Bila. (org.). Genre, race, classe. Travailler en France et au Brésil. Paris: L'Harmattan, 2016. p. 1123.

KERGOAT, Danièle. Le travail, un concept central pour les études de genre ? In : MARUANI, Margaret (org.). Je travaille, donc je suis. Perspectives féministes. Paris: La Découverte, 2018. p. 248-254.

MORENO, Renata Faleiros Camargo. Entre a família, o Estado e o mercado: mudanças e continuidades na dinâmica, distribuição e composição do trabalho doméstico e de cuidado. 2019. Tese (Doutorado em Sociologia) Faculdade de Filosofia, Letras e Ciências Humanas, Universidade de São Paulo, São Paulo, 2019.

PELLETIER, Anne-Sophie. EHPAD, une honte française, Paris : Plon, 2019.

RIMBERT, Pierre. La puissance insoupçonnée des travailleuses. Le Monde diplomatique, Paris, p. 18-19, jan. 2019. VINCENT, Jean-Marie. Critique du travail. Le faire et l'agir. Paris : P.U.F, 1987.

MOUVEMENT des Gilets Jaunes. Wikipedia, l’encyclopédie libre. Disponível em : <https://fr.wikipedia.org/wiki/ Mouvement_des_Gilets_jaunes> Acesso em : 18 dez. 2020.

Recebido em 26/02/2020 